\title{
CIDADANIA E DESENVOLVIMENTO MORAL: AS OPORTUNIDADES DA ESCOLA
}

\author{
DARLENE FERRAZ KNOENER* \\ NATÁLIA CRISTINA PUPIN SANTOS** \\ ANDRESSA CRISTINA DADÉRIO DE MELO*** \\ LARISSA DI GENOVA BONI ${ }^{* * * *}$
}

\begin{abstract}
RESUMO
A partir de investigações anteriores sobre os problemas de convivência na escola e da evidenciada necessidade da construção de programas que fomentem uma cultura de paz e preparem alunas e alunos para o exercício da cidadania, o problema da presente investigação emana das questões: Será que os caminhos teóricos e práticos para uma educação que integra o desenvolvimento de uma moralidade predominantemente autônoma e na cidadania estão bem claros para as escolas brasileiras? Quais as principais propostas sobre a promoção da convivência, da cidadania e da prevenção da violência na escola já explicitadas na legislação brasileira? Os objetivos são: Analisar as interfaces entre os fundamentos teóricos de uma educação que contribui para o desenvolvimento moral e afetivo e propostas de educação para a cidadania; descrever ações que contribuam para a escola seja um espaço de construção de sujeitos autônomos do ponto de
\end{abstract}

* Doutoranda e Mestre em Educação Escolar pela Faculdade de Ciências e Letras da Unesp.

** Mestre em Educação Escolar pela Faculdade de Ciências e Letras da Unesp. E-mail: nataliapupinsantos@gmail.com

*** Doutoranda e Mestre do programa de Educação Escolar e graduada em pedagogia pela UNESP-FCLAR. E-mail: andressa.daderio@ unesp.br.

**** Mestranda em Educação Escolar pela Faculdade de Ciências e Letras da Unesp. E-mail: ldgenova@gmail.com . 
vista moral e cientes de seu papel enquanto cidadãos. Trata-se de um estudo teórico construído a partir do levantamento de referências da legislação brasileira sobre a temática da convivência e da cidadania, além de pesquisas anteriores sobre a necessidade de a escola ser uma espaços de promoção da convivência ética e democrática, além de prevenção da violência. Os resultados das buscas indicam que as escolas brasileiras ainda têm um grande caminho a percorrer para exercer o papel que lhe é atribuído tanto do ponto de vista legal, como por seu potencial por representar um dos ambientes mais propícios para o desenvolvimento moral e cidadão. As discussões da epistemologia genética piagetiana e as contribuições da psicologia moral que dela advém fornecem a sustentação teórica a esta investigação.

Palavras-chave: desenvolvimento moral, cidadania, convivência na escola.

\begin{abstract}
Based on previous investigations about the problems of coexistence at school and the evident need to build programs that foster a culture of peace and prepare students for the exercise of citizenship, the problem of the present investigation emanates from the questions: Are the theoretical and practical paths for an education that integrates the development of a predominantly autonomous morality and citizenship very clear for Brazilian schools? What are the main proposals for the promotion of coexistence, citizenship and the prevention of violence at school already explained in Brazilian legislation? Our objectives are: To analyze the interfaces between the theoretical foundations of an education that contributes to moral and affective development and education proposals for citizenship; to describe actions that contribute to the school being a space for the construction of autonomous subjects who are aware of their role as citizens from a moral point of view. This is a theoretical study built from a survey of references in Brazilian legislation on the theme of
\end{abstract}


coexistence and citizenship, in addition to previous research on the need for the school to be a space for promoting ethical and democratic coexistence, as well as prevention of violence. The search results indicate that Brazilian schools still have a long way to go in order to perform the role assigned to them both from a legal point of view and for its potential to represent one of the most favorable environments for moral and citizen development. Discussions of Piaget's genetic epistemology and the contributions of moral psychology that flow from it provide theoretical support for this investigation.

Keywords: moral development, citizenship, coexistence at school.

\section{INTRODUÇÃO}

Desenvolvimento da moralidade e da cidadania. Qual a relação entre essas duas metas a serem alcançadas na educação das crianças e jovens? Por que são tão defendidas pelas pesquisas e documentos norteadores da educação? As respostas a estas perguntas têm grande importância para que professoras e professores possam pensar suas propostas em sala de aula. Antes de discorrermos em termos mais práticos sobre como a escola pode contribuir com o desenvolvimento da moralidade e da cidadania de suas alunas e alunos, apresentaremos uma breve fundamentação teórica a respeito dessas questões.

Primeiramente, esclarecemos que ao nos referirmos ao desenvolvimento moral, estamos partindo dos pressupostos da Psicologia Moral advinda da Epistemologia Genética Piagetiana (PIAGET, 1932/1994). Nesse sentido, a moral contempla uma dimensão que vai muito além do aprendizado e obediência a regras (LA TAILLE, 2006), pois ela traz consigo um sentimento de obrigatoriedade baseado em conteúdos como a justiça, a generosidade, a honestidade dentre tantos outros valores morais (TOGNETTA, 2009).

Além disso, no que se refere à convivência tanto na escola como na sociedade e ao exercício da cidadania, é preciso que as 
ações baseadas no dever moral tenham sentido também a partir da ética que pressupõe que o sujeito exerça sua capacidade de decidir, julgar e avaliar levando em consideração a si mesmo e o outro. Portanto, os valores morais são os de maior abrangência na vida humana, pois são norteadores de normas ou critérios de conduta que afetam todas as áreas da vida de qualquer pessoa. São os motivos que justificam as decisões e resultam na intenção da prática de condutas íntegras, solidárias, honestas, verdadeiras, que visam o bem a si e o bem a todos os outros (RICOEUR, 2014). É por isso que, para que a personalidade seja reconhecida como ética, esses valores precisam ser os mais centrais na constituição do sujeito (LA TAILLE, 2006; 2010; LA TAILLE; SOUZA; VIZIOLI, 2004).

\section{O DESENVOLVIMENTO DA MORALIDADE}

Piaget (1994), analisa a construção do conhecimento humano desde seu início e os processos de pensamento, bem como a construção da moralidade. É referência por suas concepções sobre a gênese da moral e conhecimento social. A partir de pesquisas e experimentos feitos com crianças de diferentes faixas etárias interagindo com os jogos e suas regras, apresentou uma sequência do desenvolvimento do conhecimento social e a da construção da moralidade como processos resultantes da constituição de estruturas mentais numa relação entre organismo e o meio ambiente.

Em seu prefácio à edição brasileira da obra "O juízo moral na criança” de Piaget (1932/1994), La Taille advertiu que, “...no que tange à moralidade, as relações sociais vigentes em nosso mundo raramente são baseadas na cooperação" (PIAGET, 1994, p. 19), sendo assim, um grande número de pessoas permanece durante toda a sua vida agindo de acordo estereótipos impostos pela sociedade e “... procurando inspirar suas ações em 'verdades reveladas' por deuses variados ou por 'doutores' considerados a priori como competentes e 'acima de qualquer suspeita"' (PIA- 
GET, 1994, p. 19), manifestando assim, incoerência entre suas atitudes particulares e públicas.

Piaget (1932/1994) também discorre em seus estudos sobre a "autonomia moral", uma tendência derivada da evolução da moralidade do sujeito que é "governado por si próprio" (KAMII, 2008) a partir da construção progressiva dos processos de autorregulação e cooperação. Ter uma moralidade predominantemente autônoma no sentido piagetiano, inclui a possibilidade de ser livre e usar a liberdade de maneira ética, demonstrando níveis elevados de desenvolvimento cognitivo, afetivo e social, que permitem ao sujeito a conservação de um ou de mais valores morais. Autonomia é, portanto, um estado de equilíbrio entre o bem a si e o bem ao outro, sendo este último caracterizado como universal.

Assim, o processo de construção de uma personalidade que eleja valores como a justiça, o respeito e a tolerância às diferenças - ou seja, aquele chamado de autônomo - é resultado da “cooperação" cuja essência é o operar com o outro (PIAGET, 1994). Para cooperar é preciso que as alunas e os alunos consigam exercer uma descentração cognitiva e afetiva que favorece o pensamento por reciprocidade impulsionando a cada uma e cada um a colocar-se no lugar do outro intercambiando pontos de vista (KAMII, 2008). Autonomia, portanto, é o resultado esperado do desenvolvimento cognitivo e da moralidade e só é efetivo se for construído num ambiente promotor da cooperação a partir de oportunidades em que meninas e meninos vivenciam práticas estimuladoras do autoconhecimento, da cooperação, da liberdade e da resolução de problemas. Após discorrermos sobre os principais fundamentos da Psicologia Moral, é importante também analisar questões relacionadas à construção da cidadania, especialmente pensando em nosso país.

\section{CIDADANIA: O CAMINHO}

De acordo com Carvalho (2002) a expressão "cidadania" substituiu o próprio povo na retórica política. Tem a ver com a 
relação das pessoas com o Estado e com a nação. As pessoas se tornam cidadãs à medida que passam a se sentir parte de uma nação e de um Estado. Ademais, a cidadania plena inclui direitos civis, políticos e sociais. Os direitos civis são os relacionados à vida de cada indivíduo, assim como o exercício da sua liberdade, o direito à posse de propriedades, a igualdade, a garantia de ir e vir, de escolher seu trabalho, manifestar seus pensamentos etc., ou seja, relacionam-se à liberdade individual. Os direitos políticos, não podem verdadeiramente existir na ausência dos direitos civis. Provisionam a participação dos sujeitos no governo, o direito ao voto, ou seja, o direito de autogoverno. Já os direitos sociais, garantem a participação de todos na riqueza coletiva. Incluem-se aí a educação, o trabalho, salário justo, saúde, aposentadoria. Em poucas palavras, são a garantia de mínimo bem- estar a todos, promovendo justiça social (CARVALHO, 2002).

Ao se referir especialmente à educação, o sociólogo britânico Thomas Marshall destaca que, embora definida como um direito social, esta é um pré-requisito para a expansão de todas as demais dimensões, pois entre atribuições, permite que o sujeito tome conhecimento de seus direitos e se una a outros para, organizadamente, lutar por eles. Uma população que não tem o devido acesso à educação, torna-se frágil, fator que tem sido um dos principais obstáculos à construção da cidadania civil e política (MARSHALL, 1967).

No Brasil, os direitos foram constituídos com maior ênfase nos direitos sociais, os quais precederam os demais (CARVALHO, 2002). Os direitos sociais, implantados na década de 1930 , foram determinados num período de supressão dos direitos políticos e de redução dos direitos civis por Getúlio Vargas. A falta de atrelamento dessas três dimensões - social, política e civil - geraram uma cidadania inconclusa no país. Essa característica provoca o "enaltecimento do Executivo, em detrimento dos outros dois poderes", fazendo com que o Estado ganhe certa proeminência sobre a sociedade civil (SOUZA, 2006, p. 212). 
A própria maneira como o país foi colonizado também representa dificuldades para a constituição da cidadania na sociedade brasileira. Nosso país, foi conquistado por povos seminômades que dominaram e exterminaram milhões de indígenas por meio de guerras e escravidão, priorizando os lucros resultantes da produção e comércio da cana-de-açúcar e, depois que não podiam mais escravizar os índios, adotaram uma das práticas mais negativas da constituição da história do país: a escravidão (CARVALHO, 2002).

Realizando um balanço histórico, Carvalho (2002) destaca que, do período colonial à independência brasileira, os direitos civis, sociais e políticos, que poderiam conceber um Estado de cidadãos, praticamente não existiam. A própria independência não introduziu mudanças radicais no conjunto desses direitos, pois, apesar de constituir um avanço da perspectiva dos direitos políticos, manteve a escravidão, representando grandes limitações aos direitos civis. Houve, inclusive, um tremendo retrocesso dos direitos políticos, pois não foi mais garantido o direito de voto aos analfabetos. A partir daí, somente os mais abastados e letrados estariam aptos a participar do processo político (SOUZA, 2006). Os iletrados só voltaram a depositar seu voto nas urnas em novembro de 1985, por ocasião da primeira eleição após a ditadura (BRASIL, 2016).

Como diria Goergen (2007, p. 1) "as raízes da imoralidade são muito mais profundas e alcançam o terreno comum da tradição e da cultura". Analisando esses fatos a partir de uma perspectiva moral, é possível relacionar o passado com a condição atual da sociedade brasileira. O resumo dessa realidade histórica em que havia descaso para com a educação básica, caracterizada por índices extraordinários de analfabetismo, ausência de uma sociedade política, direitos civis resguardados para poucos e da garantia de direitos políticos para pouquíssimos, esclarece muitas das mazelas presenciadas nas relações interpessoais atualmente.

Após essa breve análise da nossa própria história e a partir dos pressupostos de uma educação que garanta um ambiente 
sociomoral cooperativo, destacamos algumas demandas urgentes que precisam ser atendidas pelas escolas brasileiras de maneira planejada, sistemática e intencional. Em uma palavra, estamos falando sobre uma formação que contemple as condições necessárias para que o desenvolvimento moral aconteça garantindo a formação da personalidade ética e da autonomia, além de uma educação na cidadania que possibilite às meninas e aos meninos conhecer e usufruir de seus direitos. É por isso que apresentaremos a partir daqui algumas considerações sobre como a escola pode exercer um papel de destaque nesse sentido.

\section{O TRABALHO COM A CIDADANIA NA ESCOLA. POR QUE ELE É TÃO IMPORTANTE?}

Os termos cidadão e cidadania geralmente remetem ao indivíduo pertencente a uma comunidade e portador de um conjunto de direitos e deveres (FERREIRA; FERNANDES, 2013 apud COSTA; IANNI, 2018), mas como defendemos em nosso texto introdutório, uma cidadania plena pressupõe também autonomia moral.

O autor da obra "Pedagogia da Convivência", Xesús Jares (2008) afirma que uma educação para a cidadania tem como seu principal objetivo "formar pessoas políticas e moralmente ativas, conscientes de seus direitos e obrigações, fundamentadas em defesa da democracia e Direitos Humanos, sensíveis e solidárias com as condições do outro" (p. 57).

Ademais, é um trabalho que "permite refletir e sensibilizar sobre a convivência e o exercício da cidadania democrática na escola e em seu entorno" (JARES, 2008, p. 62) daí a importância de a escola formar estudantes capazes de exercitar a cidadania com base na convivência diária com o outro, estabelecendo uma relação de respeito mútuo, em que os direitos e deveres sejam garantidos.

As inúmeras manifestações de violência presentes na sociedade, quer seja a que acontece em relação ao gênero, o racismo, a pobreza, o terrorismo entre outros, são também temáticas 
fundamentais para estabelecer uma relação com a importância de trabalhar com a cidadania afim de promover um desequilíbrio nos sujeitos, estabelecendo reflexões sobre a necessidade de formarmos cidadãos éticos. Não é sem razão que cada vez mais investigações indicam que o caminho mais eficaz para superar esse problema é "diminuir o potencial criador de violência da escola e transformá-la num núcleo promotor de paz, gerador de não-violência, de relações solidárias e cidadãs" (PASSOS, 2004, p. 59)

Para tanto, é preciso levarmos em consideração que, o trabalho com a cidadania depende também de uma análise histórica, filosófica, jurídica, política e ética dos Direitos Humanos. Para se trabalhar com estas questões, Jares (2008) argumenta sobre a importância de compreendermos o significado do Estado de Direito laico - direitos e deveres da sociedade.

Quando nos remetemos à educação, o trabalho com a "cidadania", engloba estudos transversais podendo, assim, serem contemplados nas disciplinas como: filosofia, sociologia, direito e história (JARES, 2008). Para tanto, a escola, ao trabalhar com as disciplinas que favorecem uma reflexão sobre o tema da "cidadania", é fundamental "contemplar a globalidade dos Direitos Humanos, assim como as dimensões da cidadania democrática, global e crítica: moral, jurídica, histórica, política, filosófica e educativa" (JARES, 2008, p. 64).

\section{DOCUMENTOS NORTEADORES DA EDUCAÇÃO BRASILEIRA}

O Brasil por meio das suas Políticas Públicas mediante a promulgação das leis, diretrizes, normatizações, programas e publicações objetivou satisfazer algumas das demandas urgentes que precisam ser atendidas pelas escolas brasileiras. Dentre essas demandas destacam-se as questões raciais, de gênero, a vivência de valores morais e a participação em espaços em que a convivência democrática seja garantida. 
Esse movimento teve início com a publicação da Constituição Federal de 1988, considerada um marco no referente aos direitos e deveres de todos os cidadãos brasileiros, outro marco importante foi a publicação do Estatuto da Criança e do Adolescente o ECA (promulgado por meio da Lei no 8.069, de 13 de julho de 1990). No seu art. 53 preconiza a importância do "preparo para o exercício da cidadania" e "a igualdade de condições para o acesso e permanência na escola", lócus esse privilegiado para a vivência de valores morais e éticos.

A partir da promulgação da Lei de Diretrizes e Bases da Educação Nacional (LDB, Lei no 9394, de 20 de dezembro de 1996), em seu art. $2^{\circ}$ no qual prescreve que "a educação é um dever da família e do Estado [...], tendo por finalidade o pleno desenvolvimento do educando, seu preparo para o exercício da cidadania e sua qualificação para o trabalho".

No entanto, como se dará o preparo para o exercício da cidadania no ambiente escolar?

Em um primeiro momento, as publicações dos Referenciais Curriculares Nacionais para Educação Infantil (RCNEI, BRASIL, 1998) e dos Parâmetros Curriculares Nacionais (PCNs, BRASIL, 1998 e 2000), nortearam as primeiras ações, no ambiente escolar, voltadas para o preparo do exercício da cidadania.

O RCNEI (BRASIL, 1998) orienta e sugere atividades para serem desenvolvidas com as crianças, com o objetivo de prepará-las para o exercício da cidadania, o respeito à dignidade, de modo a no futuro exercerem os seus direitos e deveres, e propiciar o convívio harmônico com a diversidade.

Nos PCNs, temas transversais, as suas propostas de ensino estão voltadas para a construção de uma escola orientada para a formação e desenvolvimento de cidadãos éticos, que respeitem a diversidade cultural, as questões de gênero, racial e a liberdade de expressão, fortalecendo dessa maneira a formação ética e cidadã.

Permitindo assim que os meninos e as meninas vivenciem e usufruam de práticas que permitam conhecer os seus direitos e deveres a partir da primeira infância. 
O ambiente escolar tem demonstrado ser o lócus privilegiado para o desenvolvimento dessas práticas, no entanto ao analisar os dados relativos ao acesso e permanência em uma escola pública de qualidade, concluímos que esse direito não está sendo assegurado, o Plano Nacional de Educação (PNE) promulgado por meio da lei no 13.005 (BRASIL, 2014) propõe como meta a erradicação do analfabetismo funcional.

Com o objetivo de auxiliar a atingir essa meta foi instituída a Base Nacional Comum Curricular (BRASIL, 2018) "que se caracteriza por ser um documento normativo que tem como objetivo o de assegurar uma educação pública de qualidade". Os objetivos de aprendizagem e desenvolvimento, as habilidades e competências descritas neste documento possibilitam que no decorrer do processo de escolarização os conceitos de cidadania e ética permeie por todos os níveis de ensino, iniciando na Educação Infantil por meio dos campos de experiências, no Ensino Fundamental e Médio por intermédio das unidades temáticas e os objetivos de conhecimento.

Embasados nas normatizações, competências, habilidades, unidades temáticas, objetivos de aprendizagem e conhecimento que estão descritos na BNCC, apresentaremos uma sequência didática que possibilita aos professores e professoras transporem os conceitos de cidadania presentes nesse documento para o trabalho cotidiano e transversal desenvolvido nas unidades escolares, por meio do qual pretende-se também favorecer o desenvolvimento moral e ético. Proporcionando o debate em torno das questões raciais, de gênero, a vivência de valores morais e a participação em espaços em que a convivência democrática seja garantida.

\section{O COTIDIANO ESCOLAR: ALGUNS EXEMPLOS DE UM TRABALHO QUE FAVORECE O DESENVOLVI- MENTO MORAL E A EDUCAÇÃO NA CIDADANIA}

De acordo com Puig (2007) educar para a convivência impacta a estrutura do trabalho de uma escola em três vias: a 
pessoal e relacional, ou seja, a maneira de ser e de fazer dos educadores e as relações que estabelecem com os estudantes; a curricular, que tem a ver com o planejamento de atividades sistemáticas pensadas para trabalhar a formação moral e ética dos estudantes; e a institucional que implica na proposição de ações que incluem a criação de espaços de participação democrática.

Atividades organizadas em algumas escolas brasileiras já atendem importantes demandas para a educação na cidadania e contemplas essas três vias indicadas por Puig (2007). Como exemplo, podemos elencar a construção coletiva de regras desde a Educação Infantil, a implementação dos grêmios estudantis com estudantes de Ensino Fundamental e Médio, o Plenarinho ${ }^{1}$ que inclui a participação de sessões na câmara municipal de vereadores e as atividades vinculadas ao Instituto Trilhas $^{2}$ voltadas à preservação dos parques urbanos e educação socioambiental.

Sobre esse último ponto, envolvendo a educação ambiental e a geoconservação, ressaltamos que, por seu impacto transversal no trabalho na escola, são temas cada vez mais relevantes. Cabe, portanto, à escola fomentá-los tanto em sala de aula como em atividades de campo. Um dos exemplos são os trabalhos desenvolvidos a partir da obra "Dizem que toda caverna é assim..." (MENIN; TOGNETTA, 2019) que já foi adotado em algumas escolas públicas brasileiras.

Dentre estas e outras ações planejadas, sistemáticas e intencionais que a escola pode incluir em sua rotina para a educação para a convivência ética e na cidadania, enfatizamos também a necessidade da garantia dos espaços sistemáticos que façam parte das aulas para a vivência do valor da convivência democrática. Dentre esses, destacamos as assembleias de classe são um espaço para discussão de temáticas envolvendo as questões coletivas de cada turma. Além de servirem como espaço de diálogo na resolução de conflitos cotidianos, garantem alguns exercícios

https://plenarinho.leg.br

https://institutotrilhas.org.br/\#/ 
fundamentais à constituição da cidadania e da moralidade, dentre eles: o direito à fala; a reflexão sobre diferentes questões; a elaboração coletiva de propostas, o respeito à diversidade de opiniões (PUIG et al., 2000; TOGNETTA; VINHA, 2007).

\section{UM EXEMPLO DE ATIVIDADE: CRIANÇAS DAQUI E DALI}

O tema da convivência é um conteúdo da escola de crianças pequenininhas até a universidade. As pesquisas realizadas nas Ciências da Educação, Psicologia da Educação, entre outras, apontam que a escola, principalmente após um longo período pandêmico em que a escola transcende as paredes físicas de um prédio, tem, sim, o papel de organizar e sistematizar os conhecimentos de História, Geografia e Matemática. Contudo, a aprendizagem da convivência para a cidadania também é uma tarefa das instituições que educam, portanto, precisa ser também objeto de estudo contemplado na via curricular.

A partir da análise do que a literatura tem apontado sobre o trabalho sobre as questões de cidadania, exemplificamos uma atividade que pode contribuir com a formação das crianças sobre convivência e cidadania. A sequência didática a qual chamamos de "Crianças daqui e dali" tem como objetivo colaborar na construção do conhecimento sobre cidadania e no desenvolvimento moral, enfatizando o respeito à diversidade cultural, as diferenças sociais, culturais e históricas. O tempo estimado é de quatro aulas de 50 minutos e a professora ou professor pode utilizar alguns recursos como imagens de situações recentes que temos na mídia, recorte de jornais e revistas, consulta ao Estatuto da Criança e do Adolescente e recursos tecnológicos (smartphone, tablet ou computador com acesso à internet para realizar as pesquisas).

No primeiro momento, a professora ou professor organiza os estudantes em círculo e apresenta imagens ilustrativas que demonstram situações relacionadas a temas da cidadania, 
especialmente em que os direitos ou deveres de crianças e adolescentes estejam sendo garantidos ou não (crianças procurando comida no lixo, estudantes brincando na escola, adolescentes se alimentando da merenda escolar, crianças com acesso à livros na biblioteca etc.). A partir da observação das imagens, convida as alunas e os alunos a dialogarem a partir de uma questão disparadora: "O que mais chama atenção nessas imagens?".

Após a turma descrever as situações apresentadas nas imagens a professora ou professor segue provocando a reflexão utilizando novas perguntas norteadoras, dentre elas: Os direitos das crianças e adolescentes estão sendo de fatos cumpridos? Como é possível perceber o descaso com as crianças? Seria possível garantir que os direitos fossem realmente para todos? Neste ponto, para oportunizar a participação de toda a turma e ampliação das reflexões, é recomendável que a turma seja dividida em pequenos grupos.

No terceiro momento a professora ou professor poderá apresentar o Estatuto da Criança e do Adolescente e fazer a seguinte pergunta: Quais os direitos fundamentais que garantem às crianças e adolescentes a cidadania? A ideia é que levante os conhecimentos prévios das alunas e alunos que eventualmente já têm sobre o documento e em seguida a apresente o art. 227

"É dever da família, da sociedade e do estado assegurar à criança e ao adolescente, com absoluta prioridade, o direito à vida, à saúde, à alimentação, à educação, ao lazer, à profissionalização, à cultura, à dignidade, ao respeito, à liberdade e à convivência familiar e comunitária, além de colocá-los a salvo de toda forma de negligência, discriminação, exploração, violência, crueldade e opressão.” (BRASIL, 1990)

No quarto momento o docente poderá orientar as alunas e os alunos para realizarem uma nova atividade que pode ser, por exemplo, a criação de um material de propaganda sobre os direitos das crianças e dos adolescentes como uma forma de disseminação desse conteúdo em relação à importância do conhecimento do Estatuto da Criança e do Adolescente. 
A ideia é que construam panfletos com informações sobre os direitos das crianças e dos adolescentes com imagens ou frases de expressão que revelem a importância de garantir o cumprimento desses direitos. Para isso, podem utilizar as ferramentas digitais ou produzir em cartazes em folhas de papel. Se utilizarem as ferramentas digitais esse conteúdo pode ser disponibilizado no site da escola ou nas redes sociais como uma maneira de disponibilizar o conteúdo para a comunidade.

Se analisarmos a proposta sob a ótica da BNCC, é possível estabelecer relação com algumas habilidades previstas no documento como "associar a noção de cidadania com os princípios de respeito à diversidade, à pluralidade e aos direitos humanos" e "associar o conceito de cidadania à conquista de direitos dos povos e das sociedades, compreendendo-o como conquista histórica" (BRASIL, 2018).

Por fim, enfatizamos que este é apenas um exemplo de sequência de atividades práticas que podem fazer parte da via curricular de uma sala de aula que supera a concepções individualistas da educação. Como diria Passos (2004, p. 60) “a possibilidade da paz funda-se na habilidade humana, não apenas para agir, mas para agir em concerto (...) trata-se de estabelecer relações e desenvolver o sentimento de pertença, coletivo”.

\section{CONSIDERAÇÕES FINAIS}

Esta breve discussão sobre como a escola pode contribuir na formação da personalidade ética e promover uma educação na cidadania nos remete à reflexões sobre o papel tão relevante que docentes têm, especialmente, ao planejar ações sistemáticas e intencionais que provoquem reflexões, disparem discussões e ofereçam às alunas e aos alunos a oportunidade de serem protagonistas nas aulas, na construção do conhecimento e de sua própria história.

Como afirma Krawczyk (2005) “a educação não constitui a cidadania, mas sim uma condição indispensável para que a 
cidadania se constitua" (p. 800). É por isso que ressaltamos que, campanhas relacionadas à solidariedade, a amizade etc. tendem a ser insuficientes para que aconteça uma verdadeira educação moral e na cidadania, especialmente se a escola investir muito tempo na organização de eventos, mas não garantir que crianças e adolescentes sejam os principais atores dessas ações. Como diria Tognetta (2009) para construir virtudes é preciso que a educação vise a ética e isso só é possível quando estudantes pensam sobre suas próprias ações, têm oportunidade de falar sobre seus sentimentos, expressar opiniões e vivenciar mutuamente, quer sejam em relações paritárias ou com a autoridade, valores morais como, por exemplo, o respeito.

Finalmente, é preciso que equipes gestoras, docentes, funcionárias, funcionários e outros atores da comunidade escolar também colaborem para que cada aluna e aluno encontre no ambiente escolar espaços promotores do um engajamento que colabora para o exercício da cidadania, não simplesmente a nível de conhecimento, mas objetivando a transformação das pessoas a partir de um deslocamento de posições individualistas para uma posição cidadã de responsabilidade e participação na vida pública.

\section{REFERÊNCIAS}

BRASIL. Lei no 8.069, de 13 de julho de 1990. Dispõe sobre o Estatuto da Criança e do Adolescente e dá outras providências. Disponível em: http:// www.planalto.gov.br/ccivil 03/leis/18069.htm. Acesso em: 15 maio. 2021.

Portal da Base Nacional Comum Curricular, 2018. Disponível em: http://basenacionalcomum.mec.gov.br. Acesso em: 25 jan. 2018.

Constituição da República Federativa do Brasil. Disponível em: http://www.planalto.gov.br/ccivil_03/constituicao/constituicao.htm. Acesso em: 20 maio. 2021.

Senado Federal. Por 100 anos, analfabeto foi proibido de votar no Brasil. Senado notícias. Atualizado em 08 de nov. 2016. Disponível em: http:// www12.senado.leg.br/noticias/materias/2016/11/04/por-100-anos-analfabeto-foi-proibido-de-votar-no-brasil . Acesso em: 22 ago. 2017. 
Lei no 13.005/2014, de 25 de junho de 2014. Aprova o Plano Nacional de Educação vigência 2014 - 2024. Disponível em: < http://www. planalto.gov.br/ccivil_03/constituicao/emendas/emc/emc59.htm>. Acesso em 20 jan. 2020.

Lei no 9.394, de 20 de dezembro de 1996. Estabelece as diretrizes e bases da Educação Nacional. Disponível em:<http://www.planalto.gov.br/ ccivil_03/leis/19394.htm>. Acesso em: 15 nov. 2019.

Parâmetros curriculares nacionais. Brasília: MEC/SEF, 1998. Disponível em: http://portal.mec.gov.br/seb/arquivos/pdf/introducao.pdf. Acesso em: 20 maio. 2021.

CARVAlHO, J. M. Cidadania no Brasil. O longo Caminho. $3^{\text {a }}$ ed. Rio de Janeiro: Civilização Brasileira, 2002.

COSTA, M. S. I.; IANNI, A. M. Z. O conceito de cidadania. In: Individualização, cidadania e inclusão na sociedade contemporânea: uma análise teórica (on-line). São Bernardo do Campo, São Paulo: Editora UFABC, 2018, p. 43-73. Disponível em: http://books.scielo.org/id/sysng/pdf/costa-9788568576953-03. pdf. Acesso em: 22 maio. 2021.

GOERGEN, P. Educação moral hoje: cenários, perspectivas e perplexidades. Revista Educação \& Sociedade, Campinas, v. 28, n. 100 - Especial, p. 737762 , out. 2007.

JARES, X. Pedagogia da Convivência. São Paulo: Palas Athena, 2008.

KAMII, C. A criança e o número. Campinas, SP: Papirus, 2008.

KERBAUY, M. T. M. Políticas de juventude: políticas públicas ou políticas governamentais? Estudos de Sociologia, Araraquara, 18/19, p. 193-203, 2005. Disponível em: https://repositorio.unesp.br/bitstream/handle/11449/106967/ ISSN1982-4718-2005-10-18-193-206.pdf?sequence=1. Acesso em 21 ago. 2017.

KRAWCZYK, N. R. Políticas de regulação e mercantilização da educação: socialização para uma nova cidadania? Educ. Soc., Campinas, v. 26, n. 92, p. 799-819, out. 2005. Disponível em: http://www.scielo.br/scielo. php? script $=$ sci_arttext $\&$ pid $=S 0101-73302005000300005 \& \operatorname{lng}=$ pt\&nrm $=$ iso. Acesso em: 11 ago. 2017.

LA TAILLE, Y. Moral e ética: dimensões intelectuais e afetivas. Porto Alegre: Artmed, 2006. 
LA TAILLE, Y.. Moral e ética: uma leitura Psicológica. Psicologia: Teoria e Pesquisa, v. 26, n. especial, p. 105-114, 2010.

LA TAILLE, Y.; SOUZA, L.; VIZIOLI, L. Ética e educação: uma revisão da literatura educacional de 1990 a 2003 . Educação e Pesquisa, v. 30, n. 1, p. 91-108, abr. 2004.

MARSHALL. T. H. Cidadania, classe social e Status. Rio de Janeiro: Zahar Editores, 1967.

MENIN, D.; TOGNETTA, L. R. P. Toda caverna é assim... Americana-SP: Adonis, 2019.

PASSOS, S. M. Educação para Paz. In: GADOTTI, M.; PADILHA, P. R.; CABEZUDO, A. (Org.) Cidade Educadora: Princípios e Experiências. São Paulo: Cortez: Instituto Paulo Freire; Buenos Aires: Cidades Educadoras da América Latina, 2004, 58-67 p.

PIAGET, J. O juízo moral na criança. São Paulo: Summus, 1932/1994.

PUIG. J. M. Aprender a viver. In: ARANTES, Valéria Amorim (Org.). Educação e valores: pontos e contrapontos. São Paulo: Summus, 2007. 65-106 p.

PUIG. J. M. et al. Democracia e Participação Escolar. São Paulo: Moderna, 2000.

RICOEUR, P. O si mesmo como outro. São Paulo: Martins Fontes, 2014.

SANTOS, Wanderley Guilherme. Cidadania e justiça: a política social na ordem brasileira. Rio de Janeiro: Editora Campus, 1979.

SOUZA, V. A. Direitos no Brasil: necessidade de um choque de cidadania. Rev. Sociol. Polit., Curitiba, n. 27, p. 211-214, nov. 2006. Disponível em: http://www.scielo.br/scielo.php?script=sci_arttext\&pid=S0104$-44782006000200016 \& \operatorname{lng}=$ en\&nrm=iso. Acesso em: 21 ago. 2017.

TOGNETTA, L. R. P. A formação da personalidade ética: estratégias de trabalho com afetividade na escola. Campinas, SP: Mercado das Letras, 2009.

TOGNETTA, L. R. P.; VINHA, T. P. V. Quando a escola é democrática: um olhar sobre a prática de regras e assembleias na escola. Campinas, SP: Mercado das Letras, 2007. 


\section{DARLENE FERRAZ KNOENER}

Doutoranda e Mestre em Educação Escolar pela Faculdade de Ciências e Letras da Unesp. Graduada em Pedagogia pelo Centro Universitário Adventista de São Paulo (Unasp). Especialista em Psicopedagogia. Atuou na privada como professora, diretora, coordenadora pedagógica e professora universitária. Atualmente participa de projetos de pesquisa e ensino que contemplam a formação de docentes e equipes gestoras de redes públicas e particulares visando a construção de programas de promoção da convivência ética e prevenção da violência. É membro do Grupo de Estudos em Pesquisas em Educação Moral (GEPEM) da Unesp e da Unicamp. E-mail: darlene.knoener@unesp.br; Orientadora: Profa. Dra. Luciene Regina Paulino Tognetta.

\section{NATÁLIA CRISTINA PUPIN SANTOS}

Mestre em Educação Escolar pela Faculdade de Ciências e Letras da Unesp. Graduada em Pedagogia pela Faculdade de Ciências e Letras da Unesp. Realizou três iniciações científicas. Atua com formação continuada de docentes de redes públicas visando a construção de programas de promoção da convivência ética e prevenção da violência nas escolas. É membro do Grupo de Estudos em Pesquisas em Educação Moral (GEPEM) da Unesp e da Unicamp. E-mail: nataliapupinsantos@gmail.com; Orientadora: Profa. Dra. Luciene Regina Paulino Tognetta.

\section{ANDRESSA CRISTINA DADÉRIO DE MELO}

Doutoranda e Mestre do programa de Educação Escolar e graduada em pedagogia pela UNESP- FCLAR, especialista em Alfabetização e Letramento. Atuou em escolas publicas municipais como professora e coordenadora pedagógica dos anos iniciais do Ensino Fundamental. Atualmente atua como diretora de escola em um Centro de Educação e Recreação Municipal na creche e pré-escola. E-mail: andressa.daderio@unesp.br; Orientador: Prof. Dr. Silvio Henrique Fiscarelli.

\section{LARISSA DI GENOVA BONI}

Mestranda em Educação Escolar pela Faculdade de Ciências e Letras da Unesp. Graduada em Pedagogia pela Faculdade de Ciências e Letras da Unesp. Atuou como professora de Educação Infantil e é membro do Grupo de Estudos em Pesquisas em Educação Moral (GEPEM) da Unesp e da Unicamp. E-mail: ldgenova@gmail.com; Orientadora: Profa. Dra. Luciene Regina Paulino Tognetta. 